See Mun Lee, Kong Mun Lo and Edward R.T. Tiekink*

\title{
Crystal structure of 2-[(1E)-\{[1,3-dihydroxy-2- (hydroxymethyl)propan-2-yl]iminiumyl\}methyl]-5- (dodecyloxy)benzen-1-olate, $\mathrm{C}_{23} \mathrm{H}_{39} \mathrm{NO}_{5}$
}

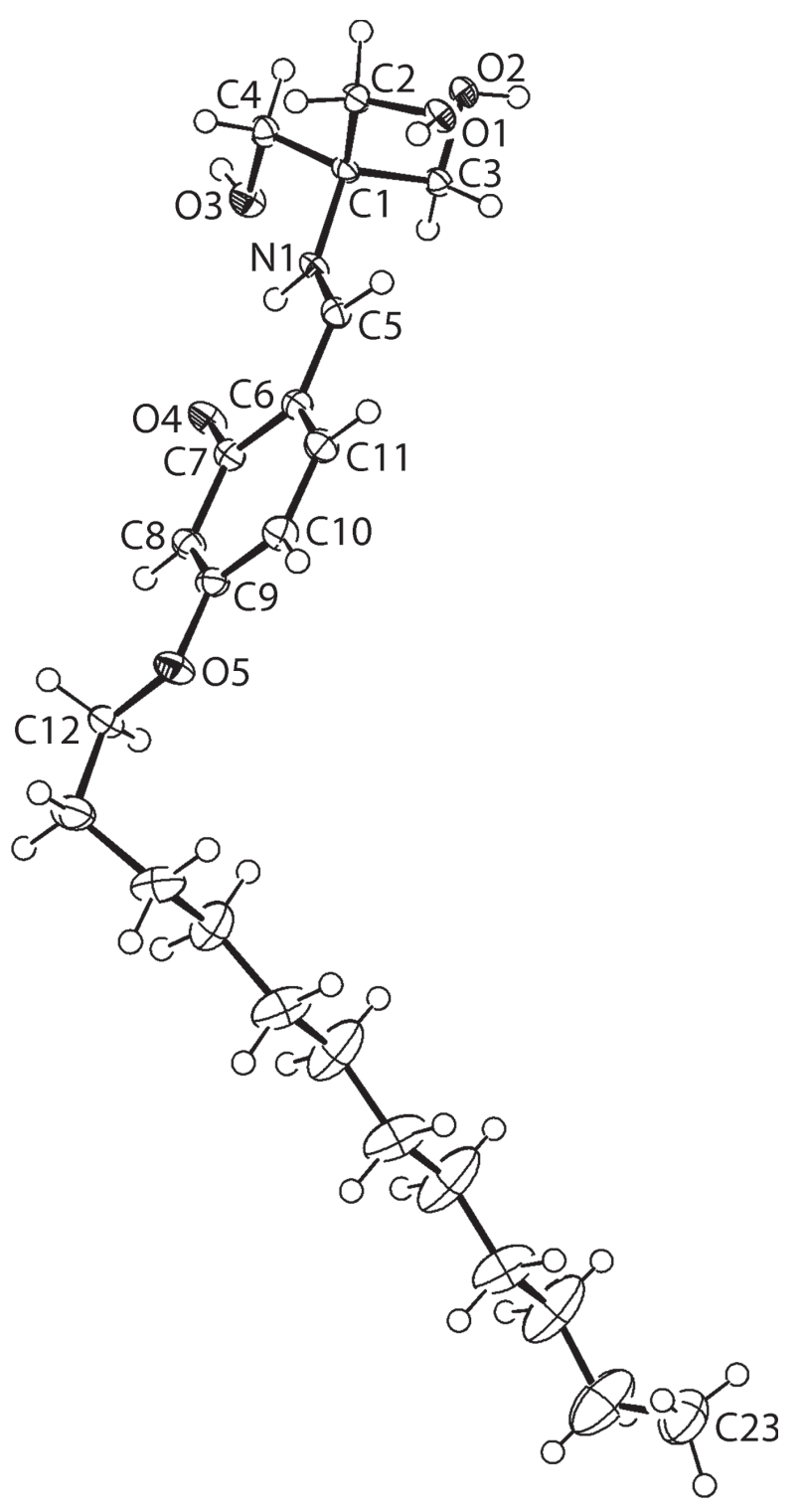

*Corresponding author: Edward R.T. Tiekink, Research Centre for Crystalline Materials, School of Science and Technology, Sunway University, 47500 Bandar Sunway, Selangor Darul Ehsan, Malaysia, e-mail: edwardt@sunway.edu.my.https://orcid.org/0000-00031401-1520

See Mun Lee and Kong Mun Lo: Research Centre for Crystalline Materials, School of Science and Technology, Sunway University, 47500 Bandar Sunway, Selangor Darul Ehsan, Malaysia https://doi.org/10.1515/ncrs-2019-0523

Received July 22, 2019; accepted October 2, 2019; available online October 14, 2019

\author{
Abstract \\ $\mathrm{C}_{23} \mathrm{H}_{39} \mathrm{NO}_{5}$, monoclinic, $P 2_{1} / c$ (no. 14), $a=26.1698(4) \AA$, \\ $b=9.4863(2) \AA, \quad c=9.0929(2) \AA, \quad \beta=97.376(2)^{\circ}$, \\ $V=2238.67(8) \AA^{3}, Z=4, R_{\mathrm{gt}}(F)=0.0539, w R_{\text {ref }}\left(F^{2}\right)=0.1580$, \\ $T=100(2) \mathrm{K}$.
}

CCDC no.: 1957130

The molecular structure is shown in the figure. Table 1 contains crystallographic data and Table 2 contains the list of the atoms including atomic coordinates and displacement parameters.

Table 1: Data collection and handling.

\begin{tabular}{ll}
\hline Crystal: & Yellow prism \\
Size: & $0.13 \times 0.03 \times 0.02 \mathrm{~mm}$ \\
Wavelength: & Cu K $\alpha$ radiation $(1.54184 \AA$ A $)$ \\
$\mu:$ & $0.68 \mathrm{~mm}^{-1}$ \\
Diffractometer, scan mode: & XtaLAB Synergy, $\omega$ \\
$\theta_{\max }$, completeness: & $67.0^{\circ},>99 \%$ \\
$N(h k l)_{\text {measured }}, N(h k l)_{\text {unique }}, R_{\text {int }}:$ & $27272,4004,0.040$ \\
Criterion for $I_{\text {obs }}, N(h k l)_{\text {gt }}:$ & $I_{\text {obs }}>2 \sigma\left(I_{\text {obs }}\right), 3452$ \\
$N(\text { param })_{\text {refined }}:$ & 275 \\
Programs: & CrysAlis \\
& WinG $[1]$, SHELX $[2,3]$, \\
\end{tabular}

\section{Source of material}

The melting point of the compound was measured on a MelTemp II digital melting point apparatus and was uncorrected. The IR spectrum was recorded using a Perkin-Elmer RX1 spectrophotometer as a Nujol mull in a $\mathrm{KBr}$ cell from 4000 to $400 \mathrm{~cm}^{-1}$. The ${ }^{1} \mathrm{H}$ NMR spectrum was recorded in $\mathrm{CDCl}_{3}$ solution on a Jeol JNM-ECA $400 \mathrm{MHz}$ NMR spectrometer with chemical shifts relative to tetramethylsilane.

4-Dodecyloxy-2-hydroxybenzaldehyde was synthesized according to a literature procedure [5]. The prepared aldehyde $(0.31 \mathrm{~g}, 1.0 \mathrm{mmol})$ was added to an ethanolic solution $(10 \mathrm{~mL})$ of tris(hydroxymethyl)aminomethane (Tokyo 
Table 2: Fractional atomic coordinates and isotropic or equivalent isotropic displacement parameters $\left(\AA^{2}\right)$.

\begin{tabular}{|c|c|c|c|c|}
\hline Atom & $x$ & $y$ & $z$ & $U_{\text {iso }} * / U_{\text {eq }}$ \\
\hline 01 & $0.89812(5)$ & 1.10031(14) & $0.50569(14)$ & $0.0184(3)$ \\
\hline $\mathrm{H} 10$ & $0.8900(9)$ & $1.055(2)$ & $0.4268(18)$ & $0.028^{*}$ \\
\hline 02 & $0.93683(5)$ & $1.17452(14)$ & $0.86963(15)$ & $0.0192(3)$ \\
\hline $\mathrm{H} 2 \mathrm{O}$ & $0.9203(9)$ & $1.236(2)$ & $0.911(3)$ & $0.029^{\star}$ \\
\hline 03 & $0.97309(5)$ & $0.82780(15)$ & $0.93578(15)$ & $0.0231(3)$ \\
\hline $\mathrm{H} 3 \mathrm{O}$ & $1.0012(6)$ & $0.829(3)$ & $0.991(3)$ & $0.035^{\star}$ \\
\hline 04 & $0.87899(6)$ & $0.57144(14)$ & $0.78365(15)$ & $0.0230(3)$ \\
\hline 05 & $0.75800(6)$ & $0.30758(15)$ & $0.45315(16)$ & $0.0247(3)$ \\
\hline N1 & $0.89831(6)$ & $0.83173(16)$ & $0.70445(17)$ & $0.0160(3)$ \\
\hline $\mathrm{H} 1 \mathrm{~N}$ & $0.9040(9)$ & $0.7597(17)$ & $0.764(2)$ & $0.019^{\star}$ \\
\hline $\mathrm{C} 1$ & $0.93071(7)$ & $0.95905(19)$ & $0.7299(2)$ & $0.0146(4)$ \\
\hline $\mathrm{C} 2$ & $0.94145(7)$ & $1.0290(2)$ & $0.5849(2)$ & $0.0172(4)$ \\
\hline $\mathrm{H} 2 \mathrm{~A}$ & 0.9698 & 1.0977 & 0.6078 & $0.021^{\star}$ \\
\hline $\mathrm{H} 2 \mathrm{~B}$ & 0.9534 & 0.9558 & 0.5195 & $0.021^{\star}$ \\
\hline $\mathrm{C} 3$ & $0.90380(7)$ & $1.05744(19)$ & $0.8288(2)$ & $0.0166(4)$ \\
\hline $\mathrm{H} 3 \mathrm{~A}$ & 0.8708 & 1.0908 & 0.7747 & $0.020^{\star}$ \\
\hline H3B & 0.8964 & 1.0065 & 0.9187 & $0.020^{\star}$ \\
\hline C4 & $0.98251(7)$ & $0.9067(2)$ & $0.8083(2)$ & $0.0182(4)$ \\
\hline $\mathrm{H} 4 \mathrm{~A}$ & 0.9997 & 0.8465 & 0.7405 & $0.022^{*}$ \\
\hline $\mathrm{H} 4 \mathrm{~B}$ & 1.0053 & 0.9878 & 0.8385 & $0.022^{\star}$ \\
\hline $\mathrm{C} 5$ & $0.86144(7)$ & $0.8098(2)$ & $0.5962(2)$ & $0.0170(4)$ \\
\hline $\mathrm{H} 5$ & 0.8521 & 0.8854 & 0.5296 & $0.020^{*}$ \\
\hline C6 & $0.83438(7)$ & $0.6815(2)$ & $0.5712(2)$ & $0.0172(4)$ \\
\hline $\mathrm{C} 7$ & $0.84556(7)$ & $0.5621(2)$ & $0.6670(2)$ & $0.0174(4)$ \\
\hline $\mathrm{C} 8$ & $0.81897(8)$ & $0.4341(2)$ & $0.6276(2)$ & $0.0195(4)$ \\
\hline $\mathrm{H} 8$ & 0.8253 & 0.3535 & 0.6892 & $0.023^{*}$ \\
\hline C9 & $0.78412(7)$ & $0.4261(2)$ & $0.5006(2)$ & $0.0189(4)$ \\
\hline C10 & $0.77303(8)$ & $0.5445(2)$ & $0.4064(2)$ & $0.0212(4)$ \\
\hline $\mathrm{H} 10$ & 0.7487 & 0.5375 & 0.3197 & $0.025^{\star}$ \\
\hline C11 & $0.79790(8)$ & $0.6684(2)$ & $0.4427(2)$ & $0.0204(4)$ \\
\hline $\mathrm{H} 11$ & 0.7906 & 0.7480 & 0.3801 & $0.024^{\star}$ \\
\hline C12 & $0.76677(8)$ & $0.1823(2)$ & $0.5427(2)$ & $0.0238(5)$ \\
\hline $\mathrm{H} 12 \mathrm{~A}$ & 0.7570 & 0.1989 & 0.6428 & $0.029 *$ \\
\hline $\mathrm{H} 12 \mathrm{~B}$ & 0.8036 & 0.1557 & 0.5530 & $0.029 *$ \\
\hline C13 & $0.73421(9)$ & $0.0668(2)$ & $0.4658(3)$ & $0.0323(5)$ \\
\hline $\mathrm{H} 13 \mathrm{~A}$ & 0.7410 & -0.0217 & 0.5226 & $0.039^{\star}$ \\
\hline H13B & 0.7448 & 0.0519 & 0.3662 & $0.039 *$ \\
\hline C14 & $0.67641(9)$ & $0.0967(3)$ & $0.4485(3)$ & $0.0383(6)$ \\
\hline $\mathrm{H} 14 \mathrm{~A}$ & 0.6697 & 0.1840 & 0.3894 & $0.046^{\star}$ \\
\hline H14B & 0.6583 & 0.0187 & 0.3911 & $0.046^{\star}$ \\
\hline C15 & $0.65341(9)$ & $0.1135(3)$ & $0.5903(3)$ & $0.0396(6)$ \\
\hline $\mathrm{H} 15 \mathrm{~A}$ & 0.6655 & 0.0345 & 0.6570 & $0.048^{\star}$ \\
\hline H15B & 0.6668 & 0.2018 & 0.6388 & $0.048^{\star}$ \\
\hline C16 & 0.59630(10) & $0.1175(4)$ & $0.5752(3)$ & $0.0480(7)$ \\
\hline $\mathrm{H} 16 \mathrm{~A}$ & 0.5848 & 0.1952 & 0.5063 & $0.058^{\star}$ \\
\hline H16B & 0.5835 & 0.0287 & 0.5264 & $0.058^{\star}$ \\
\hline C17 & $0.57043(11)$ & $0.1349(4)$ & $0.7065(4)$ & $0.0597(9)$ \\
\hline $\mathrm{H} 17 \mathrm{~A}$ & 0.5798 & 0.2295 & 0.7474 & $0.072^{\star}$ \\
\hline $\mathrm{H} 17 \mathrm{~B}$ & 0.5857 & 0.0654 & 0.7806 & $0.072^{*}$ \\
\hline C18 & $0.51451(11)$ & $0.1220(4)$ & $0.6989(3)$ & $0.0540(8)$ \\
\hline $\mathrm{H} 18 \mathrm{~A}$ & 0.4994 & 0.1906 & 0.6234 & $0.065^{\star}$ \\
\hline $\mathrm{H} 18 \mathrm{~B}$ & 0.5054 & 0.0271 & 0.6585 & $0.065^{\star}$ \\
\hline C19 & $0.48748(11)$ & $0.1401(5)$ & $0.8267(4)$ & $0.0707(11)$ \\
\hline $\mathrm{H} 19 \mathrm{~A}$ & 0.4950 & 0.2370 & 0.8636 & $0.085^{\star}$ \\
\hline H19B & 0.5040 & 0.0754 & 0.9041 & $0.085^{\star}$ \\
\hline
\end{tabular}

Table 2 (continued)

\begin{tabular}{lrrrr}
\hline Atom & $\boldsymbol{x}$ & $\boldsymbol{y}$ & $\boldsymbol{z}$ & $\boldsymbol{U}_{\text {iso }}{ }^{*} \boldsymbol{U}_{\text {eq }}$ \\
\hline C20 & $0.43222(10)$ & $0.1204(4)$ & $0.8214(3)$ & $0.0542(8)$ \\
H20A & 0.4244 & 0.0245 & 0.7820 & $0.065^{*}$ \\
H20B & 0.4156 & 0.1872 & 0.7464 & $0.065^{*}$ \\
C21 & $0.40593(12)$ & $0.1355(5)$ & $0.9530(4)$ & $0.0708(11)$ \\
H21A & 0.4110 & 0.2342 & 0.9872 & $0.085^{*}$ \\
H21B & 0.4245 & 0.0751 & 1.0311 & $0.085^{*}$ \\
C22 & $0.35122(12)$ & $0.1044(5)$ & $0.9484(4)$ & $0.0739(12)$ \\
H22A & 0.3420 & 0.1169 & 1.0499 & $0.089^{*}$ \\
H22B & 0.3461 & 0.0035 & 0.9228 & $0.089^{*}$ \\
C23 & $0.31410(12)$ & $0.1865(4)$ & $0.8462(4)$ & $0.0554(8)$ \\
H23A & 0.3146 & 0.2851 & 0.8784 & $0.083^{*}$ \\
H23B & 0.2794 & 0.1477 & 0.8466 & $0.083^{*}$ \\
H23C & 0.3237 & 0.1812 & 0.7456 & $0.083^{*}$ \\
\hline
\end{tabular}

Chemical Industry, $0.12 \mathrm{~g}, 1.0 \mathrm{mmol}$ ) and refluxed for $3 \mathrm{~h}$. The filtrate was evaporated slowly until a yellow precipitate was formed. The precipitate was recrystallized from methanolhexane by slow evaporation to yield yellow crystals. Yield: 0.16 g (39.1\%). M.pt: 383-384 K. IR ( $\left.\mathrm{cm}^{-1}\right) 3233$ (br) v(O-H), 1634 (s) v(C-N), 1525 (s) v(C-O), 1047 (s) v(C-O), 1016 (m) $v(\mathrm{C}-\mathrm{O}) .{ }^{1} \mathrm{H}$ NMR $\left(\mathrm{CDCl}_{3}, \mathrm{ppm}\right): \delta 0.86\left(\mathrm{~s}, 3 \mathrm{H}, \mathrm{CH}_{3}\right), 1.24-1.79$ (m, 20H, $\left.\mathrm{CH}_{2}\right), 3.70-4.00\left(\mathrm{~m}, 8 \mathrm{H}, \mathrm{OCH}_{2}\right), 6.40(\mathrm{~d}, 1 \mathrm{H}, \mathrm{Ph}-\mathrm{H})$, $6.51(\mathrm{~d}, 1 \mathrm{H}, \mathrm{Ph}-\mathrm{H}), 7.37(1 \mathrm{H}, \mathrm{Ph}-\mathrm{H}), 8.41(\mathrm{~s}, 1 \mathrm{H}, \mathrm{N}=\mathrm{CH}) ; \mathrm{OH}$ and $\mathrm{NH}$ protons were not observed.

\section{Experimental details}

The $\mathrm{C}$-bound $\mathrm{H}$ atoms were geometrically placed $(\mathrm{C}-$ $\mathrm{H}=0.95-0.99 \AA)$ and refined as riding with $U_{\text {iso }}(\mathrm{H})=1.2-$ $1.5 U_{\text {eq }}(\mathrm{C})$. The $\mathrm{O}$ - and $\mathrm{N}$-bound $\mathrm{H}$-atoms were located in a difference Fourier map but were refined with distance restraints of $\mathrm{O}-\mathrm{H}=0.84 \pm 0.01 \AA$ and $\mathrm{N}-\mathrm{H}=0.88 \pm 0.01 \AA$, respectively, and with $U_{\text {iso }}(\mathrm{H})$ set to $1.5 U_{\text {eq }}(\mathrm{O})$ and $1.2 U_{\text {eq }}(\mathrm{N})$, respectively. As evident from the figure, the long chain suffers from typical disorder. Careful modelling did not reveal any chemically useful information and so, the simpler model was retained.

\section{Comment}

In connection with recent studies of diorganotin Schiff bases derived from tris[(hydroxymethyl)aminomethane] [6, 7], largely motivated by the promising cytotoxicities they exhibit [6], the structure of the title tris[(hydroxymethyl) aminomethane] Schiff base derivative, featuring an appended $n$-dodecyl substituent, was prepared and studied crystallographically.

The molecular structure is shown in the figure $(50 \%$ displacement ellipsoids) and crystallography confirms the molecule existing as a zwitterion in the solid-state. 
Proton transfer has occurred from the phenol group to the imine-nitrogen atom (see the figure). An intramolecular, charge-assisted medium-strong imine- $\mathrm{N}-\mathrm{H} \cdots \mathrm{O}$ (phenoxide) hydrogen bond is evident [N1-H1n ...04: $\mathrm{H} 1 \mathrm{n} \cdots \mathrm{O} 4=1.918(17) \AA$, N1 $\cdots \mathrm{O} 4=2.639(2) \AA$ with angle at $\left.\mathrm{H} 1 \mathrm{n}=138.9(19)^{\circ}\right]$. The $\mathrm{C} 5-\mathrm{N} 1$ imine bond length is 1.303(3) $\AA$ and the configuration about this bond is $E$. The imine residue is co-planar with the phenyl ring to which it is connected with the $\mathrm{N} 1-\mathrm{C} 5-\mathrm{C} 6-\mathrm{C} 11$ and $\mathrm{N} 1-\mathrm{C} 5-\mathrm{C} 6-\mathrm{C} 7$ torsion angles being $-175.12(18)$ and $0.5(3)^{\circ}$, respectively. The alpha-methylene atom of the $n$-dodecyl chain is co-planar with the phenyl ring as seen in the values of the $\mathrm{C} 12-\mathrm{O} 5-\mathrm{C} 9-\mathrm{C} 8$ and $\mathrm{C} 12-\mathrm{O} 5-$ C9-C10 torsion angles of $0.9(3)$ and $-179.71(17)^{\circ}$, respectively. A kink is then evident in the chain with the $05-\mathrm{C} 12-\mathrm{C} 13-$ C14 and C12-C13-C14-C15 torsion angles of $-61.5(2)$ and $-61.9(3)^{\circ}$, respectively, being indicative of - syn-clinal conformations. The remaining methylene atoms of the chain have an almost all-trans conformation with the maximum deviation in torsion angles being $-169.7(2)^{\circ}$, for C13-C14-C15-C16.

There is a single literature precedent for the structure reported herein, that is, with a methyl rather than a $n$-dodecyl substituent [8]. This is also zwitterionic and was characterised as a monohydrate.

In the crystal, the 01-hydroxy group forms a chargeassisted hydrogen bond with the phenoxide- $\mathrm{O}$ atom [01$\mathrm{H} 10 \cdots \mathrm{O} 4^{\mathrm{i}}: \mathrm{H} 1 \mathrm{O} \cdots \mathrm{O} 4^{\mathrm{i}}=1.766(18) \AA$ 员 $01 \cdots \mathrm{O} 4^{\mathrm{i}}=2.5927(19) \AA$ with angle at $\mathrm{H} 1 \mathrm{o}=167.5(18)^{\circ}$ for symmetry operation (i) $x$, $3 / 2-y,-1 / 2+z]$ while the other hydroxy groups participate in hydroxy $-\mathrm{O}-\mathrm{H} \cdots \mathrm{O}$ (hydroxy) hydrogen bonds [02$\mathrm{H} 2 \mathrm{O} \cdots \mathrm{O} 1^{\mathrm{ii}}: \mathrm{H}_{2} \mathrm{O} \cdots \mathrm{O} 1^{\mathrm{ii}}=1.90(2) \AA \AA 02 \cdots \mathrm{O} 1^{\mathrm{ii}}=2.7279(19) \AA$ with angle at $\mathrm{H} 2 \mathrm{O}=166(2)^{\circ}$ and $03-\mathrm{H} 30 \cdots \mathrm{O} 2^{\mathrm{iii}}$ : $\mathrm{H} 30 \cdots \mathrm{O} 2^{\mathrm{iii}}=1.93(2) \AA \AA 03 \cdots \mathrm{O} 2^{\mathrm{iii}}=2.7600(19) \AA$ with angle at $\mathrm{H} 3 \mathrm{o}=176(3)^{\circ}$ for (ii) $x, 5 / 2-y, 1 / 2+z$ and (iii) $2-x$, $2-y, 2-z]$. The molecules assemble head-to-head to form a bi-layer, in the $b c$-plane, sustained by the aforementioned hydrogen bonding interactions. This allows for the inter-digitation of the $n$-dodecyl chains.

Using established procedures [9] and Crystal Explorer 17 [10], the calculated Hirshfeld surfaces were analysed as were the full and delineated two-dimensional fingerprint plots. The presence of multiple conventional hydrogen bonding interactions is reflected in a significant contribution of $\mathrm{H} \cdots \mathrm{O} / \mathrm{O} \cdots \mathrm{H}$ contacts, that is, $15.4 \%$ to the overall surface.
This notwithstanding, by far the greatest contribution is made by $\mathrm{H} \cdots \mathrm{H}$ contacts, at $72.9 \%$, reflecting the hydrophobic interactions in the inter-layer region. The only other contribution to the surface contacts of note are from $\mathrm{H} \cdots \mathrm{C} / \mathrm{C} \cdots \mathrm{H}$ contacts of $10.9 \%$, which arise largely from methylene-C3$\mathrm{H} \cdots \pi$ (phenyl) and methyl-C23- $\mathrm{H} \cdots \pi$ (phenyl) interactions within the bi-layer constructed from the $\mathrm{O}-\mathrm{H} \cdots \mathrm{O}$ hydrogen bonding.

Acknowledgements: Sunway University Sdn Bhd is thanked for financial support of this work through Grant no. STRRCTR-RCCM-001-2019.

\section{References}

1. Rigaku Oxford Diffraction: CrysAlis ${ }^{\text {PRO }}$. Rigaku Corporation, Oxford, UK (2018).

2. Sheldrick, G. M.: A short history of SHELX. Acta Crystallogr. A64 (2008) 112-122.

3. Sheldrick, G. M.: Crystal structure refinement with SHELXL. Acta Crystallogr. C71 (2015) 3-8.

4. Farrugia, L. J.: WinGX and ORTEP for Windows: an update. J. Appl. Crystallogr. 45 (2012) 849-854.

5. Lai, C. K.; Chang, C.-H.; Tsai, C.-H.: Liquid crystalline properties of bis(salicylaldiminato)copper(II) complexes: the first columnar discotics derived from salicylaldimine. J. Mater. Chem. 8 (1998) 599-602.

6. Lee, S. M.; Sim, K. S.; Lo, K. M.: Synthesis, characterization and biological studies of diorganotin(IV) complexes with tris [(hydroxymethyl)aminomethane] Schiff bases. Inorg. Chim. Acta 429 (2015) 195-208.

7. Lee, S. M.; Lo, K. M.; Tiekink, E. R. T.: Crystal structure of (2([1,1-bis(hydroxymethyl)-2-oxyethyl]iminomethyl)-5-(n-decyl) phenolato)-dimethyl-tin(IV), $\mathrm{C}_{23} \mathrm{H}_{39} \mathrm{NO}_{5} \mathrm{Sn}$. Z. Kristallogr. NCS 234 (2019) 1337-1340.

8. Li, Z.-Y.; Jia, G.-K.; Yuan, L.; Bai, P.-F.; He, H.; Zhou, Q.: Syntheses, crystal structures and biological activities of three new Schiff bases derived from substituted salicylaldehyde and tris base. Chin. J. Struct. Chem. 36 (2017) 1797-1802 .

9. Tan, S. L.; Jotani, M. M.; Tiekink, E. R. T.: Utilizing Hirshfeld surface calculations, non-covalent interaction $(\mathrm{NCl})$ plots and the calculation of interaction energies in the analysis of molecular packing. Acta Crystallogr. E75 (2019) 308-318.

10. Turner, M. J.; McKinnon, J. J.; Wolff, S. K.; Grimwood, D. J.; Spackman, P. R.; Jayatilaka, D.; Spackman, M. A.: Crystal Explorer v17. The University of Western Australia, Australia (2017). 